\title{
Electrical Engineering Design Course at Memorial University of Newfoundland
}

\author{
Tariq Iqbal, Associate Professor, Faculty of Engineering, MUN \\ tariq@mun.ca
}

\begin{abstract}
The Engi. 5800 Electrical Engineering Design course was introduced in 2008 to the electrical engineering curriculum of Memorial University of Newfoundland $(M U N)$. This compulsory course is offered in term 5 and typical enrolment is about 25 to 30 students. The nature of this course is fundamentally different from other lecture-based courses taught at the Faculty of Engineering. In this course, students work in groups on two design projects at a time. One design project i.e. emergency light design is a guided design project while the other is a student led design project. Design projects require students to follow a hierarchy of design process which includes: the general product definition, specifications and requirements, functional block diagrams, definition of specification of functional blocks for circuit level synthesis and implementation, system integration, simulation or modeling, testing and verification. All projects are a significant technical challenge and require students to apply their knowledge of electrical engineering learned through courses in the electrical engineering program. The course is designed to provide a meaningful design experience and encourage confidence building in students. This paper describes course details, organization, design methodology, types of projects and course outcome.
\end{abstract}

\section{Introduction}

Faculty of Engineering and Applied Science offers a full-time 141 credit hour Bachelor of Engineering (Co-operative), Electrical Engineering Major - General Option. This requires eight academic terms and four work terms. The Engi. 5800 Electrical Engineering Design course was introduced in the electrical engineering curriculum in 2008. Other universities also offer similar courses e.g. [1]. This compulsory 3 credit hours course is offered in term 5 and typical enrolment is about 25 to 30 students. So far the author has taught this course four times at MUN. Teaching a design course is always challenging. The nature of this course is fundamentally different from other lecture-based courses taught at the Faculty of Engineering and Applied Science. In this course, students work in groups on two design projects at a time. Typically there are two students in each group. One guided design project is about an emergency light system design while the other design project is a student led design project. At the start of a term, students are given a list of project titles to choose from and they select one design project and complete that to a finished presentable and marketable product form. All students also design and complete an emergency light system design. About 12-14 lectures are also delivered as part of the course. This course also involves significant writing, development of product packaging and a brochure including final product specifications. All assigned projects are a technical challenge and require students to apply their knowledge of electrical engineering learned through courses in term 1 through 4 in the electrical engineering program. The course is designed to provide a meaningful design experience and encourage confidence building in students.

Other universities design courses typically involve only one project [2] or they are based on around a fixed platform given to all students [3]. Final year design projects are more involved and complex [4]. At MUN final year design project courses (Engi7803 and Engi8853), in electrical engineering spans two terms (7 and 8) and it is based on larger groups (3-5 students). Design in electrical engineering is very important and MUN electrical engineering program stresses that by offering three design courses in the program. Typical design projects are open ended but some universities have taken a mixed approach of simulation and project building [5]. At MUN, in a design project we require students to follow a hierarchy of design process which includes: the general product definition, specifications and requirements, functional block diagrams, definition of specification of functional blocks for circuit level synthesis and implementation, system integration, simulation or modeling, testing and verification. We believe such complete design projects at term 5 level lead to significant student learning and help develop a great student interest in electrical engineering.

\section{Course Organization}

As mentioned above Engi5800 is based on two design projects. All students do emergency light design project. It is a guided design project where design is 
covered in the class and design tasks are organized in a set of five labs. Details of course organization is given below in table 1 . More details may be found at http://www.engr.mun.ca/ tariq/Engi5800.htm

Table 1. A list of labs and projects

Design Labs:

The following five labs lead to design and demonstration of an emergency light system.

1. Design, implement and test a $120 \mathrm{~V}, 60 \mathrm{~Hz}, 10 \mathrm{VA}, 8-0-8 \mathrm{~V}$ stepdown transformer.

2. Design and test a $120 \mathrm{~V}$ to $+5 \mathrm{~V}$ regulated power supply with indicators and a USB connector.

3. Design, implement and test a $12 \mathrm{~V}, 7 \mathrm{Ah}$ lead-acid battery microcontroller based PWM charger.

4. Design a PIC16F684 based automatic portable emergency light control circuit.

5. Package, verify, demonstrate and present a product brochure of the designed system.

Design Projects 1 to 20 offered in 2011 are listed below. These projects are changed every year so that students cannot copy design ideas from the previous years. Students select project and group member within first few days of the course. All circuits in a project are built on prototyping boards (i.e. no breadboards are allowed). All finished projects are expected in boxes with appropriate connectors and labels. In the last week of the term students verify, demonstrate their projects and present project overview and technical specifications in a brochure to two external examiners.

Projects list: (2011)

P1. Design a $100 \mathrm{~W}$ push-pull type $12 \mathrm{VDC}$ to $120 \mathrm{VAC}$ single pulse modulated inverter.

P2. Design a dual axis programmed solar tracking system.

P3. Design a DC motor position servo with a maximum error of one degree.

P4. Design a PIC, relays and two-phase induction motor based position servo.

P5. Design an incandescent bulb light intensity controller with a

LDR feedback.

P6. Design a small water jet height control system.

P7. Design a DC motor based inverted pendulum system.

P8. Design a temperature controlled hair dryer system.

P9. Design a temperature controlled small instant water heating system.

P10. Design a synchronous generator automatic voltage regulator.

P11. Design an intersection traffic lights controller with traffic sensors.

P12. Design a large LCD or seven segments displays based clock.

P13. Design a two stepper motors based large analog clock.

P14. Design a five sensors and a PC based weather station.

P15. Design a coins counting system.

P16. Design a store number of customers counting system.

P17. Design a touch less liquid soap dispenser system.

P18. Design a web based remote stepper motor controller and light sensor reading system.

P19. Design a $0-5 \mathrm{~kg}$ digital scale.

P20. Design a 0-5000rpm optical tachometer.

Fundamentals of electrical design, introduction to microcontrollers, programming and interfacing is taught in the class. Typically, fifteen lectures are delivered in the class during the early part of the term. These lectures are required since students coming to the course are not familiar with the PIC microcontroller programming and interfacing. Design of emergency light system is also covered in the class. There are 24, 3 hour scheduled lab sessions in the course. Technical support, lab facilities, instructor and teaching assistants are available during the lab sessions to help students with their design projects. Evaluation scheme and more details of the course project organization are given below in table 2. A D2L course website is used to help manage and organize the course. There is no textbook for this course. A book [6] is used in this course as a reference text.

Table 2. Evaluation and project deadlines

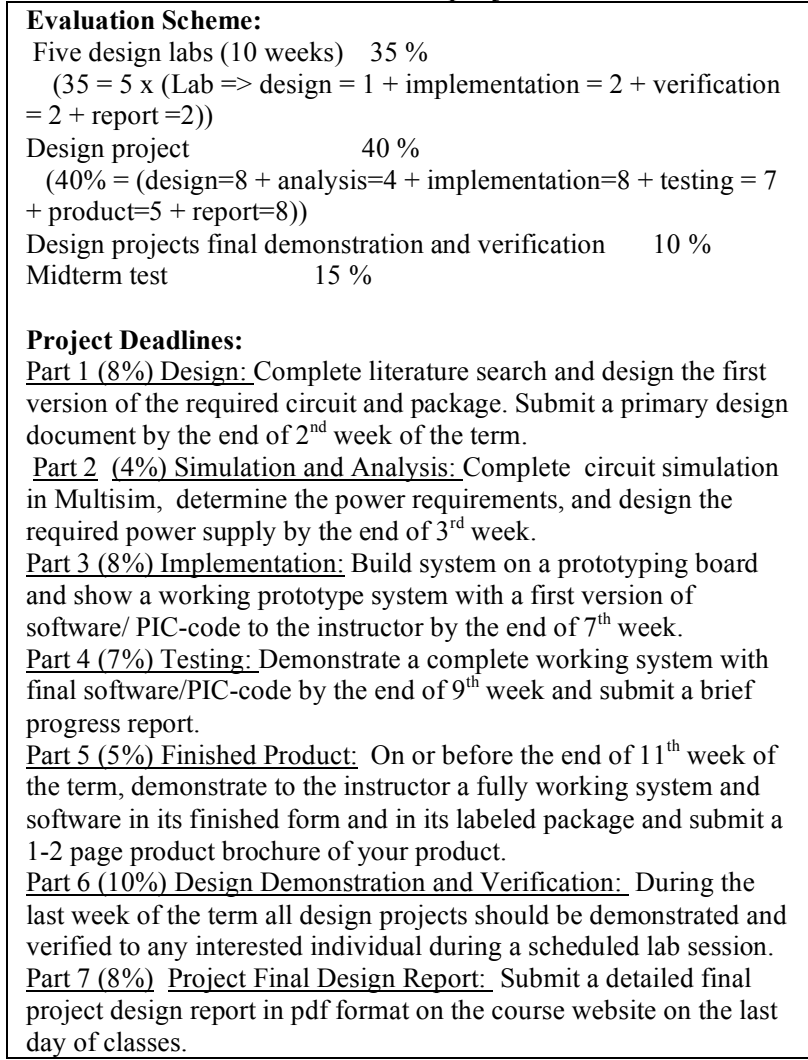

\section{Lessons Learned So Far}

The course organization described above has some advantages. Engi 5800 is the first design course in the electrical engineering program in which students design and build systems. One guided design project helps them understand the design procedure and steps that need to be taken in that process. The second design project helps them practice the skill they have developed. My experience so far teaching the course tells me that this works very well. The students take great interest in their projects and spend a lot of time and effort completing the projects. This is a three 
credit hours course but time spent on this course is lot more than time spent on other courses offered in the term. This sometime effect students' performance in other courses in the term but helps them learn time management. For the department this is a costly course. Money spent on this course and required lab resources are far more than other courses offered in the electrical engineering program. Some students also end up spending some money from their pocket.

The main difficulties that I have faced so far are (1) every year, come up with a new list of inexpensive projects with more are same difficulty level, (2) develop a fair grading scheme for a wide variety of projects, (3) develop a background so that I can provide on time effective help to all students, (4) find two new willing teaching assistants every year who have strong background in electronic design and microcontroller programming, (5) provide all students effective and timely feedback on their progress reports, and help students in their projects designs and troubleshooting in the lab, (6) make a list of electronic items that students will be using in their projects during the term and order that before the start of the term, and (7) convince the Chair and department to commit funds for this course. Formal lectures help students learn microcontrollers, programming and interfacing. (It is not covered formally in any other course). Lectures help me to bring all students knowledge to a certain level. One advantage of student selected projects is that they select a project they are interested in, spend outstanding effort to complete the design and get outstanding results. Every year I come up with a new set of projects. Projects for the year 2011 are listed in table 1 while projects for the year 2008 are given table 3. A comparison of projects can give a good idea of instructor's challenge of coming up with a new set of projects every year.

Table 3. A list of projects offered in 2008 .

\section{Projects for the year 2008:}

P1. Design a 48V PMG based wind turbine controller

P2. Design a MPPT controller for a PV module

P3. Design a Micro-hydro system load controller

P4. Design a 24V Air-X wind turbine controller

P5. Design a 1-axis solar tracking system

P6. Design a 48V linear dump load controller

P7. Design a ON/OFF type non-essential load controller

P8. Design a gas generator auto start/stop system

P9. Design a gas generator to $48 \mathrm{~V}$ battery charging system

P10. Design a user ac load monitor to measure and record voltage and current

P11. Design a hybrid power system input \& output currents monitor and status indicator P12. Design a lead acid battery monitor and fuel gauge

P13. Design a PC based 8-hour in advance power production forecast system
There is no formal presentation in this course but at the end of the term students present their project specification and a working systems to two external examiners. Examiners mark their projects out of $10 \%$ and students spend a great deal to time and effort to get that right. This is also a very good learning experience for students. This term 5 design course greatly helps them prepare for the term 7 and 8 capstone project. The main benefits of this course for students are (1) go through all design steps and all aspects of a product design, (2) learn to work in a group effectively, (3) learn and practice project management, (4) apply, practice and improve their knowledge of electrical engineering, (5) learn to complete a project on time following a time line and a start with a set of system design specifications, and (6) deliver a working system with a set of final system specifications in a brochure.

\section{Example Design Projects}

Every year students design an emergency light system and work on a student lead design project. Figure 1 below shows a block diagram of the emergency light system. It is based on PIC16F684 as the controller. An emergency light circuit proto-type is shown in the figure 2. PIC programming is done using Mikrobasic.

Figure 1. Block diagram of emergency light system

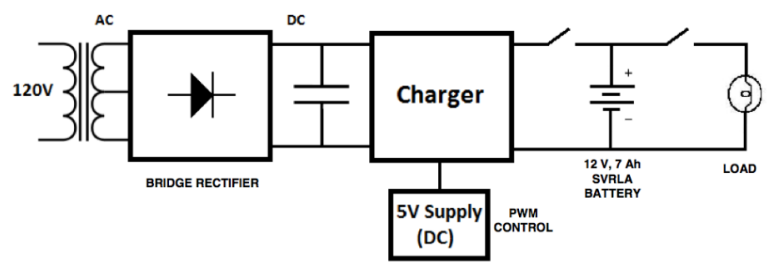

Figure 2. Circuit prototype for emergency light

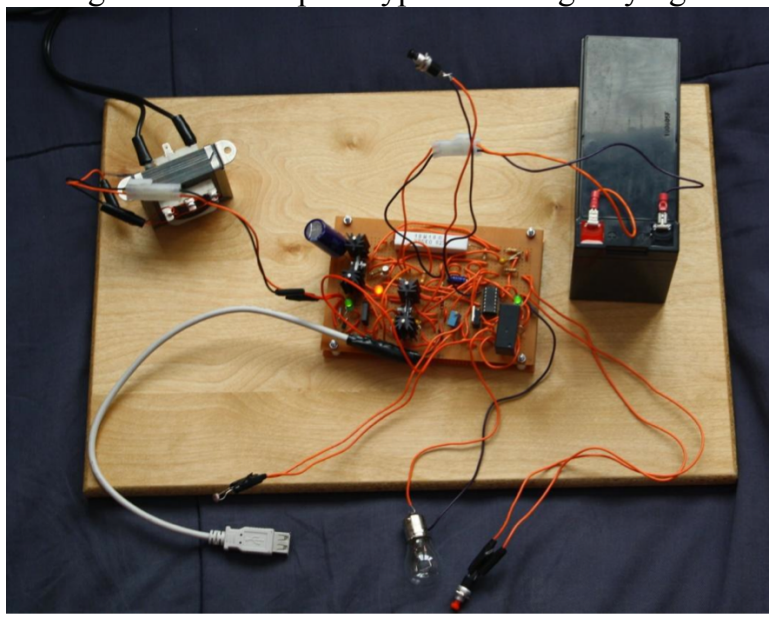


Figure 3. Flow chart of emergency light controller

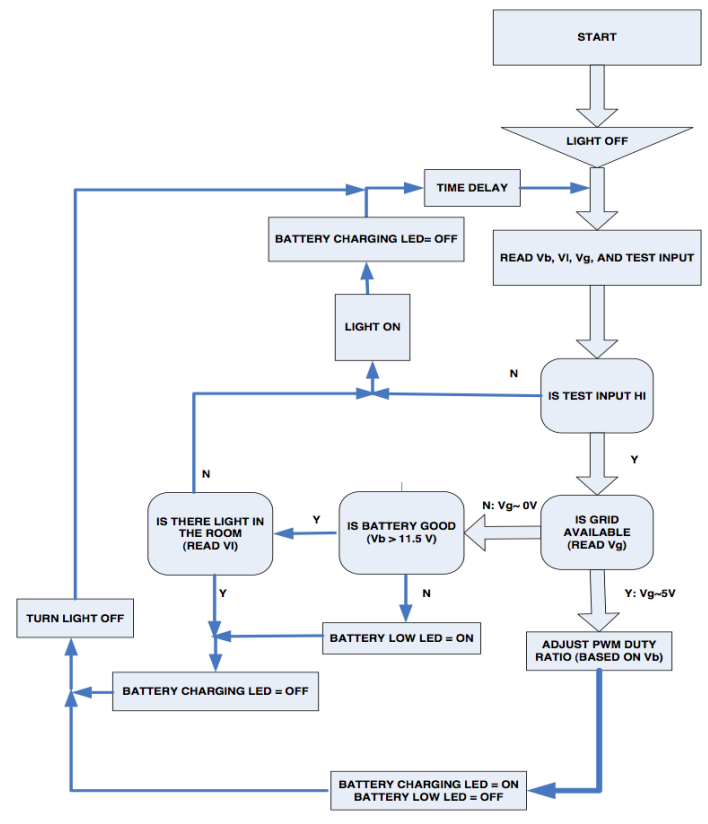

Figure 4. Test results of emergency light system

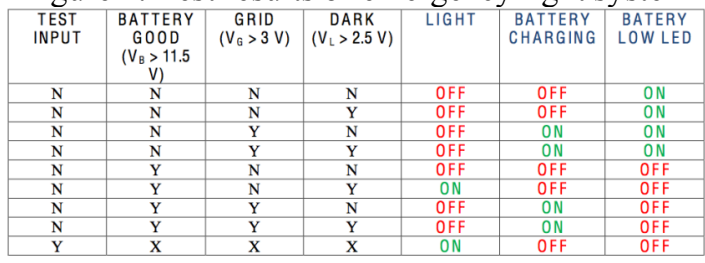

Figure 5. Brochure for the emergency light

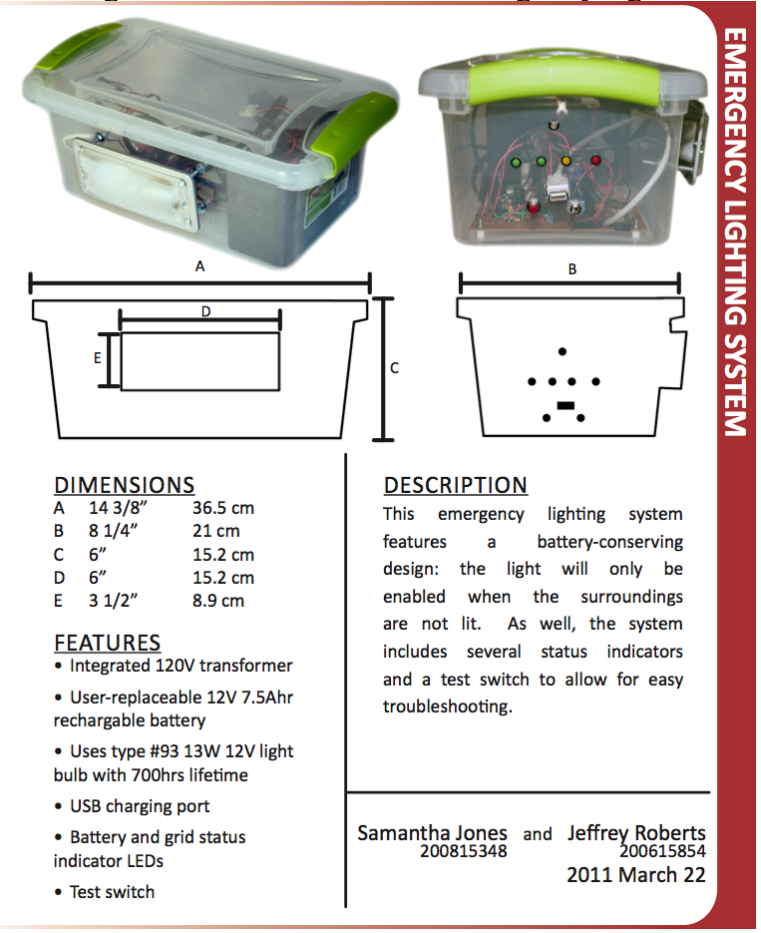

A typical student developed flow chart of emergency light controller is shown in figure 3. Students test their system in all possible conditions and a set of test results is presented in figure 4. At the end student package the emergency light system and produce a system brochure. An example of student brochure is shown in figure 5.

As mentioned in table 1, students also work on a design project. Most of the design projects are microcontroller based. Students learn programming and design and build their systems in the lab. Projects change every year. Figure 6 below shows an inverted pendulum project that a group of two students completed in 2011. Figure 7 shows a student produced brochure of a temperature controlled hot air blower.

Figure 6. Inverted pendulum system

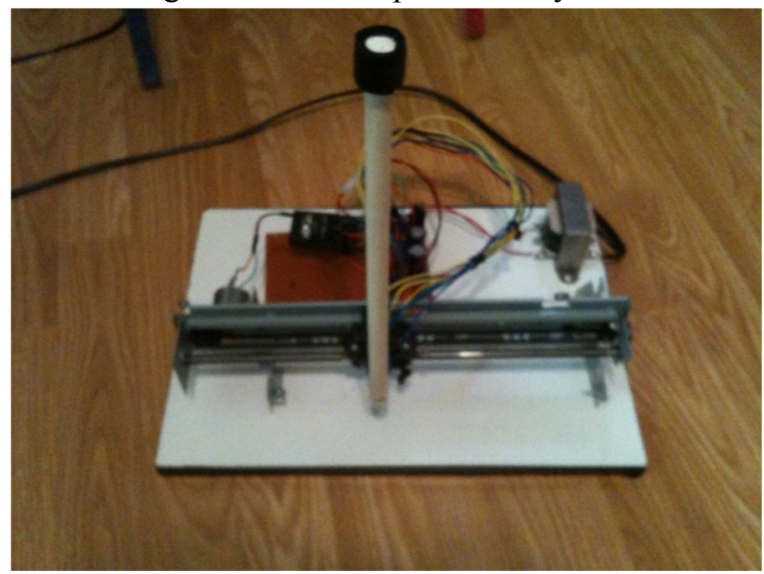

This is a picture of our finalized project, which includes our pendulum, DC motor, track and cart, completed circuit and transformer.

Figure 7. Temperature controlled hot air blower

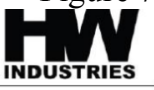

ACU DRI-2575

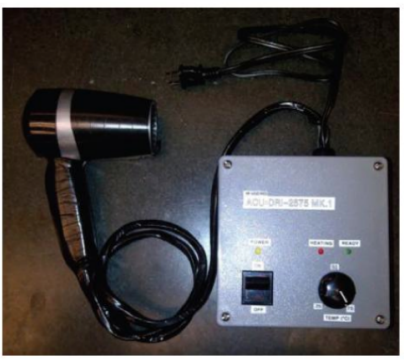
The ACU-DRI-2575 represents a breakthrough in hair drying technology. Through advance
control circuitry, it is able to actively regulate and maintain a constant output temperature over a range of $25^{\circ} \mathrm{C}$ to $75^{\circ} \mathrm{C}\left( \pm 5^{\circ} \mathrm{C}\right)$. The simple, easily accessible user interface allows states of the system. Three indicator LEDs are present which show when the system is on, the heating element is on, and when the set point has been reached so the system is ready to use. A large temperature selection dial and
power switch are mounted on the top of the unit for easy control. The sturdy countertop contro unit is sealed and has a water resistant cable strain relief, protecting the unit from splashing perfect for any end-user, including residences and hotels.

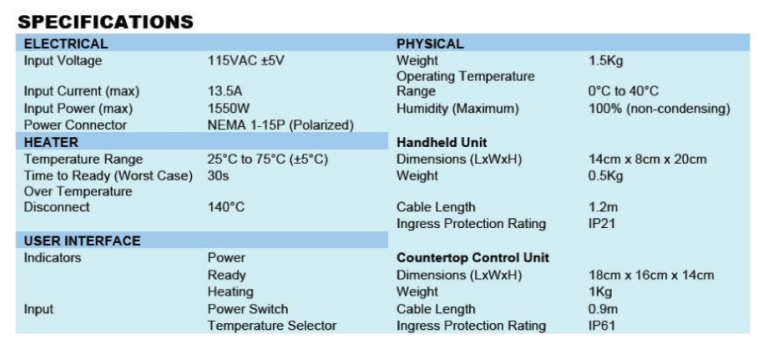


Some projects are control oriented. In 2010 a group of two students worked on a 2-axis programmed solar tracking system. It was a PIC16F877 controlled system. A system block diagram is shown in figure 8 while the final product is shown in figure 9. A linear actuator and a DC motor were used in the project and system had its own power supply. The project was a success and students demonstrated a fully functional system to the external examiners.

Figure 8. Block diagram of 2-axis tracking system

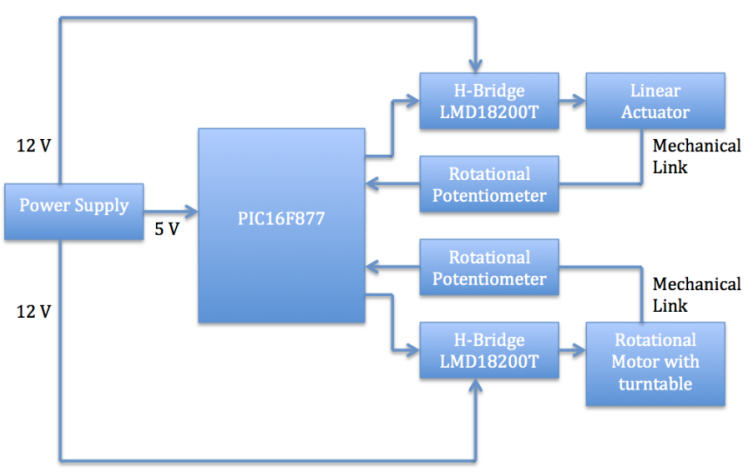

Figure 9. Two axis solar tacking system

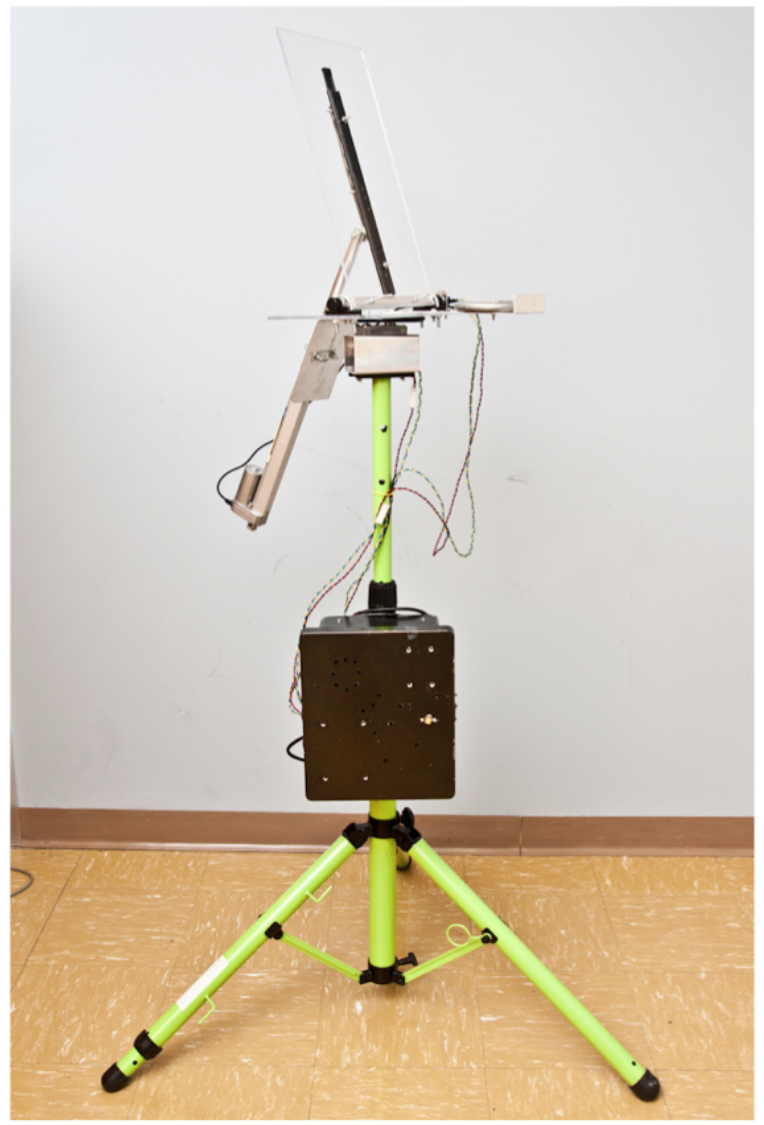

In 2009, a group of students designed and developed a lead acid battery fuel gauge system. Basically using two sensors they recorded and logged the battery voltage and current during charge and discharge cycles. Energy stored in the battery was calculated and displayed on two 7-segment displays. Battery voltage and current could also be displayed. Figure 10 and 11 show the designed system circuit diagram and the final product. Project was a success and lead to a great learning experience for the students.

Figure 10. Circuit diagram of battery fuel gauge

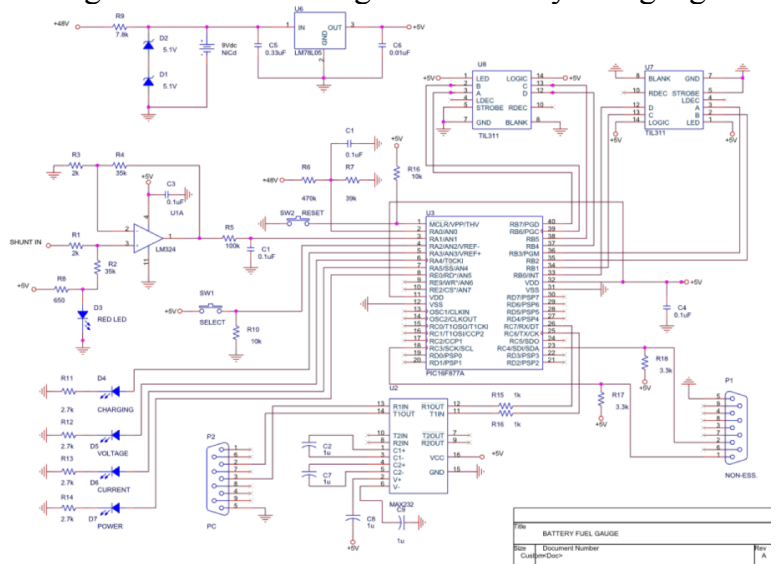

Fig 11. Battery fuel gauge.

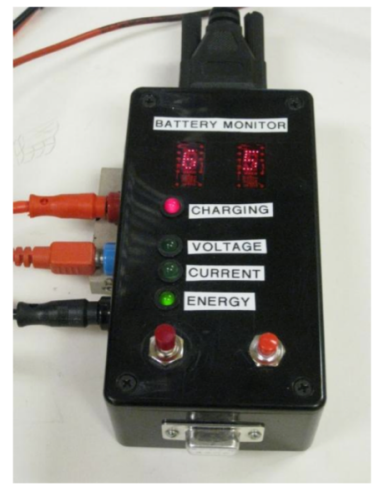

Fig 12. Soap dispenser

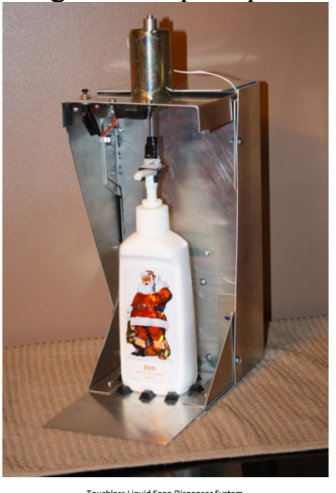

Figure 13. DC position servo

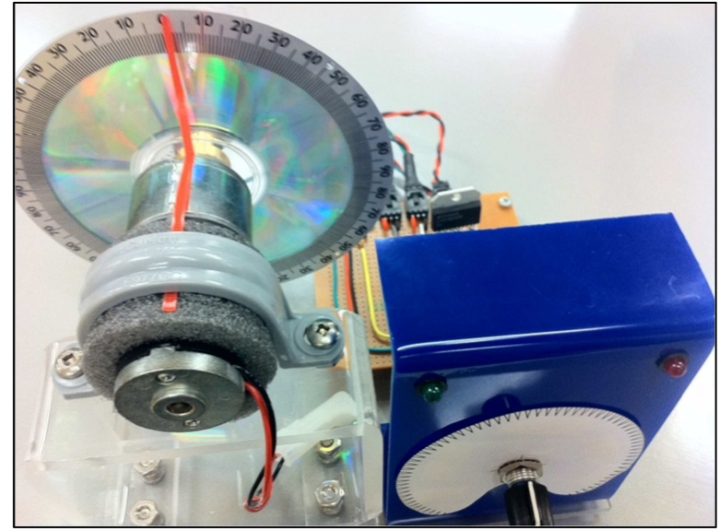


In 2011 a group of students designed and developed a touch less liquid soap dispenser. It is shown in figure 12. The system was controlled by a PIC16F684 and it was based on a student designed solenoid and an infrared sensor. Students also designed and built its power supply. In 2010 a group of students designed and built a DC motor based position servo system. Their designed system is shown in figure 13. That PIC16F684 based system with a feedback from a servo potentiometer also had a PID controller implemented in the software. In 2009 a group of students designed and developed a 1-axis solar tracker. They used a commonly available geared satellite dish motor. They removed its controller and designed another controller to meet their objectives. System was programmed such that it moves 15 degrees per hour to track the sun and tilt angle was adjusted according the desired location latitude. The designed system with a small PV module is shown in figure 14.

Figure 14. 1-axis programmed solar tracker

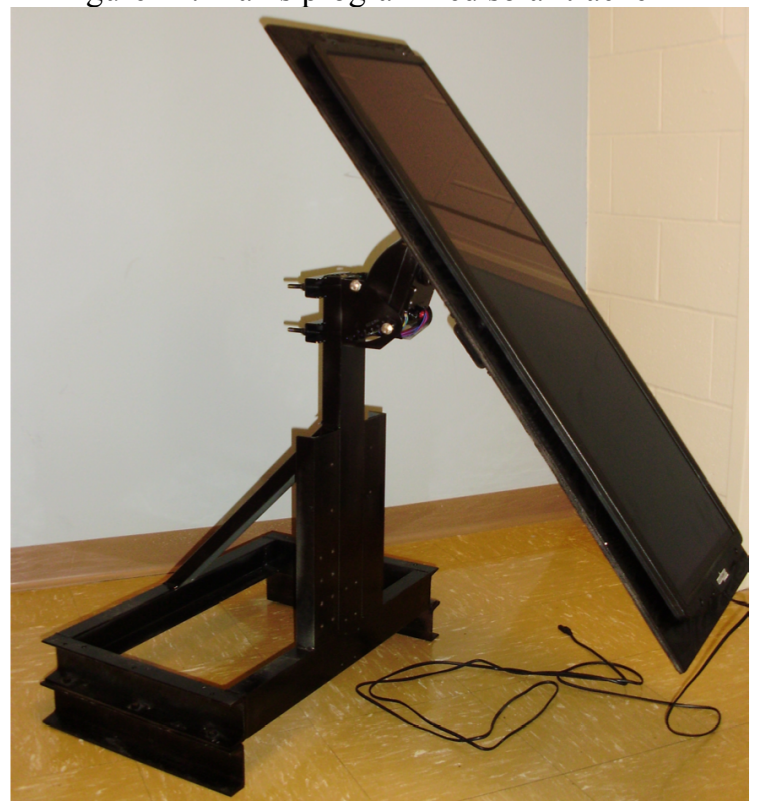

Over a period of four years, a wide variety of projects have been successfully designed and implemented in the course. Great students interest in the course and projects have been noted. In the middle of the term students also write a class test. Class test covers some aspects of electronics, interfacing and microcontroller programming. Typical wait of the class test is only $10-$ $15 \%$. Class test help make sure that all students learn, demonstrate knowledge of interfacing and microcontroller programming. Project final reports, that students submit at the end of the term clearly indicate great student learning and interest in the course. There is no final exam in the course. So far this course has been a success and class average is about $85 \%$.

\section{Conclusions}

This paper described Memorial University of Newfoundland Engi 5800 course details, organization, design methodology, types of projects and course outcome. This compulsory course is offered every year in term 5 in the electrical engineering program. Design projects in the course require students to follow a hierarchy of design process. The course also involves significant writing, development of product packaging and brochures including final product specifications. A new set of designed projects is offered every year. Authors have noted great student interest and learning in the course. The course is designed to provide all students a practical design experience, encourage students to work in groups, write reports and show progress throughout the course. The course also helps confidence building in students and it has been a great success so far.

\section{References}

[1]. Mark J. Paulik and Mohankrishnan, Teaching Electrical Engineering Design: A Ten Year Summary, in Proceedings of IEEE Frontier in Education Conference 1994. PP. 538542 .

[2]. Robert L. Mertz, A Capstone Design Course, IEEE transactions on Education, Vol. 40, No.1, Feb. 1997.

[3]. Ashraf Saad, Mobile Robotics As The Platform for Undergraduate Capstone Electrical and Computer Engineering Design Projects, in Proceedings of $34^{\text {th }}$ ASEE/IEEE Frontiers in Education Conference, October 2023, 2004.

[4]. Howard Li, Education in Electrical Engineering through A Design Project, CCECE '09 conference, 3-6 May, St. John's, NL, 2009.

[5]. David V. Kerns, Sherra E. Kern, et. al., The Search for Design in Electrical Engineering Education, The first IEEE International Workshop on Electronic Design, Test and Applications (DELTA '02) 2002.

[6]. J. Eric Salt and Robert Rothery, Design for Electrical and Computer Engineers, John Wiley \& Sons, 2002. 